\title{
Exploring parenting variables associated with sweetness preferences and sweets intake of children
}

\author{
Taejung Woo and Kyung-Hea Lee \\ Department of Food and Nutrition, Changwon National University, 20 Changwondaehak-ro, Uichanggu, Changwon-si, Gyeongnam, 51140, Korea
}

BACKGROUND/OBJECTIVES: Excessive sugar intake is one of the causes associated with obesity and several chronic diseases prevalent in the modern society. This study was undertaken to investigate the effect of parenting variables based on the theory of planned behavior, on the sweetness preferences and sweets intake of children.

SUBJECTS/METHODS: Parents and their children ( $n=103$, aged 5-7 years) were enrolled to participate in a survey for this study, after providing the required informed consent. Parents were asked to fill out a self-administered questionnaire at their residence. The sweetness preference test for children was conducted at a kindergarten (or daycare center) by applying the one-on-one interview method.

RESULTS: The children were divided into two clusters categorized by the K-mean cluster analysis: Cluster 1 had higher sweetness preference (0.42 M sugar, 35\%; $0.61 \mathrm{M}$ sugar, 65\%); Cluster 2 exhibited lower sweetness preference $(0.14 \mathrm{M}$ sugar, $9.5 \% ; 0.20 \mathrm{M}$ sugar, 9.5\%; $0.29 \mathrm{M}$ sugar, 81\%). Cluster 1 had a higher frequency of sweets intake $(P<0.01)$, and lower sweets restriction $(P<0.05)$ and nutrition quotient score $(P<0.05)$. Sweets intake was negatively correlated with the nutritional quotient $(r=$ -0.204, $P<0.05)$. The behavioral intention of parents was higher in cluster $2(P<0.05)$, while affective attitude, feeding practice, and reward were higher in cluster $1(P<0.001, P<0.05$, and $P<0.01$, respectively). Furthermore, behavioral intention of parents showed a negative correlation with affective attitude $(r=-0.282, P<0.01)$ and feeding practice $(r=-0.380, P<0.01)$, and a positive correlation with subjective norm $(r=0.203, P<0.05)$ and parenting attitude $(r=0.433, P<0.01)$.

CONCLUSIONS: This study indicates that the sweetness preferences and sweets intake of children is related to the parent's affective attitude, feeding practice and reward. We suggest that to reduce the sugar consumption of children, guidelines for access to sweets and pertinent parenting practices are required.

Nutrition Research and Practice 2019;13(2):169-177; https://doi.org/10.4162/nrp.2019.13.2.169; pISSN 1976-1457 elSSN 2005-6168

Keywords: Child, food preferences, parenting, theory of planned behavior

\section{INTRODUCTION}

Preference of sweet taste over other tastes is a universal characteristic of humans, irrespective of age and culture $[1,2]$. It is reflected in the increased consumption of saccharides in processed products of the food [3]. Excessive sugar intake not only causes carious of teeth and overweight, but also triggers metabolic diseases [4]. WHO has presented guidelines of healthy diet, and recommends the intake of saccharide (free sugar) to be less than $10 \%$ of the intake of daily energy (preferably, less than $5 \%$ for better results). Domestic guidelines have therefore been set for the intake of saccharide to be less than $10-20 \%$ of the intake of daily energy, comprising less than $10 \%$ added sugar [5]. To accomplish objectives of the policies of nutrition or healthcare developed for health promotion of the public, establishing scientific educational strategies based on the theory of education for effective propagation and implementation have been well recognized. The availability and accessibility of foods for children are affected by the dietary practice and attitudes of their parents. Parents play significant roles in the contemporary food environment, where availability of foods with cheap and high-density energy are abundant [6,7]. In particular, the attitudes and behavior of mothers toward such foods significantly influences their children. It has been reported that overweight and obesity in infants and young children is dependent on the dietary behaviors of their mothers [8]. Therefore, approaches in diverse perspectives to develop educational strategies for parents needs to be encouraged for the formation of desirable food preferences of children.

Recent increase in saccharide consumption through sweets and drinks is ascribable to changes in the dietary environment that enables convenient intake of energy. Such changes are evidenced by higher intake rate of carbonated drinks by adolescents who frequently exhibit higher incidences of metabolic syndromes [9]. Unfortunately, food preference are difficult to change once they are established, resulting in varied conse-

\footnotetext{
This research was supported by Changwon National University in 2018.

${ }^{\S}$ Corresponding Author: Kyung-Hea Lee, Tel. 82-55-213-3514, Fax. 82-55-281-7480, Email. khl@changwon.ac.kr

Received: December 23, 2018, Revised: January 12. 2019, Accepted: March 7, 2019

This is an Open Access article distributed under the terms of the Creative Commons Attribution Non-Commercial License (http://creativecommons.org/licenses/by-nc/3.0/) which permits unrestricted non-commercial use, distribution, and reproduction in any medium, provided the original work is properly cited.
} 
quences depending on the initial experiences of foods [10]. Therefore, strategies that help children develop desirable food preferences in the contemporary obesogenic environment are important for sustaining a healthy lifestyle. Reed and McDaniel [11] reported that sweetness preferences of people is simply distinguished into two types: 1) type 1 pattern showing increased sweetness preference in accordance with the concentration of sweetness to a certain peak from where the degree of preference would start to decrease, and 2) type 2 showing constant increase in degree of sweetness preference, proportional to the concentration of sweetness to a certain peak from where the degree of sweetness preference remains constant. People having preferences of type 2 sweetness tend to experience no "excessive sweet taste". Although a definite association of consequences of sweets intake with preference to sweet taste has not been established, the behaviors of consuming sweet foods are been reported to be affected by the dietary environment and culture, consequently affecting an individual's health. To help children possess desirable food choice and preference regarding sweet taste, there is the requirement for exploring the effects of sweet foods that have been experienced in childhood.

The present study was therefore designed to investigate parenting and sweets preferences of children, and subsequent to the study findings, suggest educational strategies for parents to help reduce sugar consumption in children. We applied the theory of planned behavior (TPB) for designing the current study as a theoretical framework. It explains the behavioral motivation associated with health of individuals effectively, and promotes behavioral intention (BI), thereby increasing the probability of behavioral implementation [12]. To our knowledge, only a few papers have investigated the dietary behavior of children based on TPB [12,13]. This study could explore meaningful variables based on TPB to control sweet preferences amongst children.

\section{SUBJECTS AND METHODS}

\section{Study plan}

The present study was designed based on the theory of planned behavior, to analyze parenting variables for sweetness preferences and sweets intake amongst children. The study method and survey variables were selected from those suggested in previous studies $[1,6,12,14]$. The protocol of the present study was approved by the Institutional Review Board of Changwon National University (Approval No.: 1040271-201603- HR-005).

\section{Study subjects}

Children aged 5-7 years from kindergartens or daycare centers and residing with their parents in Changwon, Korea, were enrolled for participation. To invite participation, the study purposes were forwarded to the kindergarten and daycare centers registered at the "Center for Children's Foodservice Management" in Changwon. Five educational institutions (four daycare centers and one kindergarten) expressed their intention to participate in the study and were duly selected. A total of 126 copies of guidelines, questionnaires designed to be filled out by parents, and consent to test of sweetness preferences of children, were distributed to each residence, where parents were asked to fill out the respective questionnaires. A total of 103 questions, including consent to the sweetness preference test, were collected. Children of parents who responded with the questionnaire were selected for the final analysis. Researchers visited the daycare centers and kindergarten of these children to do a one-on-one test for the sweetness preference. The survey was carried out during the period August 2016 to November 2016.

\section{Survey methods}

The questionnaire for parents comprised general questions, and questions related to sweets intake frequency of children, nutrition quotient (NQ) of children, variables based on the theory of planned behavior, and parenting practice included feeding practice, parenting attitude and reward. The list of favorite foods for children [15], registered in the Standards of Nutritive Components of high-calorie low-nutrient foods notified by Ministry of Food and Drug Safety, was referred to for the investigation of frequency of sweets intake. The intake frequency of 8 sweets categories (cookie, candy, bread, chocolate, milk beverage, ice cream, beverage, carbonated drink) per week was then analyzed. In addition, a 5-point scale ranging from 'never free to choose' to 'always free to choose' was employed to appraise the restriction degree on children for the choice of these 8 sweets. This scale was used to determine the sweets restriction by parents, and also assessed the feeding practice of parents. NQ developed by the Korean Nutrition Society was also used to compare quality of diet and dietary behavior of children, corresponding to their sweets intake frequency and sweetness preferences. NQ is a nutritional screening tool developed based on foods intake and dietary behavior of high-grade students in elementary schools. It encompasses five factors: balance (5 questions: intake frequency of whole grain, fruits, white milk, eggs, and legumes), diversity (3 questions: intake frequency of colorful vegetable, kimchi, and diverse side dishes), moderation (5 questions: intake frequency of fast foods, sweet foods, instant noodle, night eating, and street foods), regularity (3 questions: meal regularity, eating breakfast, and exercise), and practice (3 questions: hand washing, chewing well, and checking nutrition label). The score ranges from 0 to 100 (< 10 'lowest', 10-24 'low', 25-74 'moderate', 75-89 'high', and $\geq 90$ 'highest') $[16,17]$. Recently, it has been employed in analyzing and evaluating the quality of diet and dietary behavior of infants and young children $[18,19]$.

For creating parenting variables that affect sweetness preference and sweets intake of children, we referred to previous studies $[1,6,12,14,20]$. Components of the theory of planned behavior were also included in each question, as follows: one question for $\mathrm{Bl}$, two questions for affective attitude (Cronbach's a: 0.629), three questions for cognitive attitude (Cronbach's a: 0.668), two questions for subjective norm (Cronbach's a: 0.898), and one question for perceived behavioral control. Regarding parenting practice, we included three questions on feeding practice (Cronbach's a: 0.545), three questions on parenting attitudes (Cronbach's a: 0.620), and one question on reward; all responses were based on a 5-point scale scoring ranging from 1 (not at all) to 5 (always). Bl was used to assess the parents' intention in taking action to give lesser sweets to the 
child. Affective attitude meant positive feeling on sweets intake of children, and cognitive attitude was related to negative outcome expectation on sweets intake of children. Subjective norm described parent's beliefs that other people's effect on sweets intake of children. Perceived behavioral control was related to a parent's confidence in controlling sweets intake. The components of parenting practice are described as follows: feeding practice as restriction in eating sweets, parenting attitude as a parent's judgment for positive parent-child interaction, and reward as using sweets as a reward.

\section{Sweetness preference test}

The test procedure and the concentration of sugar content in specimens were set by referring to previous studies $[1,20]$. As specimens selected for the evaluating sweetness preference, chocolate drinks comprising a mixture of $100 \mathrm{~mL}$ of whole milk (4\% of milk fat), $6 \mathrm{~g}$ of cocoa powder, and varying contents of white sugar (sugar concentration: $0.14 \mathrm{M}, 0.20 \mathrm{M}, 0.29 \mathrm{M}, 0.42$ $M$, and $0.61 \mathrm{M}$ ) were prepared by the researchers. The amount of cocoa powder to be added to the whole milk was determined by the average content of cocoa powders contained in seven commercial products of milk drinks with cocoa.

Researchers visited each daycare center and kindergarten to conduct one-on-one interviews. By considering characteristics of the children, the researchers demonstrated the method for tasting sweets to each subject, and imparted sufficient training. Children were then asked to make a choice of the drink they would like to drink every day, from among the presented ones. The process to select respective drinks according to their preferences was organized in two stages. The first stage was designed to select either Specimen 2 (concentration of sugar content $0.20 \mathrm{M}$ ) or Specimen 4 (concentration of sugar content $0.42 \mathrm{M}$ ). The second stage was designed to present to children who selected Specimen 2 (the drink of lesser sweetness) with Specimens 1, 2, and 3, while children who selected Specimen 4 were presented Specimens 3, 4, and 5. Children were asked to select the one they would like to drink every day from among the presented three specimens. All subjects were guided to drink specimens in the order from lower to higher concentration of sugar content. After drinking each specimen, a cup of fresh water was given to each subject to rinse their mouth before drinking the next specimen. The subjects were allowed to spit out specimens of drinks or fresh water provided for the test at their discretion. Subjects were provided with approximately $5-10 \mathrm{~mL}$ of each drink.

\section{Statistical analysis}

Data were analyzed using the statistical package SPSS Version 24.0. Non-hierarchical cluster analyses (k-mean cluster analyses) were carried out to compare influential factors affecting sweetness preference of children. Two clusters of comparatively constant members in each cluster were defined and distinguished. The collected data are described in terms of frequency, percentage (\%), mean, and standard deviation. To compare intergroup differences in general characteristics of subjects, sweetness preference, sweets intake frequency, NQ, and parenting variables (such as $\mathrm{Bl}$, attitude, subjective norm, feeding practice, parenting attitude, and reward), we applied the t-test. Degrees of restriction on sweets by parents were distinguished into two groups (k-means cluster analysis). Intergroup differences in sweetness preference, sweets intake frequency, and NQ were also analyzed by t-test. Correlation of parenting variables with sweetness preference, sweets intake frequency, and NQ of children were examined using Pearson's correlation analysis. Reliability of coefficient of parenting variables are expressed in values of Cronbach's Alpha. Statistical significance is set at $P<0.05$.

\section{RESULTS}

\section{Characteristics of subjects}

General characteristics of children are summarized in Table 1. The mean age was $6.3 \pm 0.5$ years. There were $51(49.5 \%)$ boys and $52(50.5 \%)$ girls. The average height and weight were $111.7 \pm 6.4 \mathrm{~cm}$ and $20.1 \pm 3.2 \mathrm{~kg}$, respectively. Obesity of children was defined by the Body Mass Index (BMI) \%ile and was categorized as follows: underweight $(n=10,9.7 \%)$, normal weight ( $n=86,83.5 \%)$, and overweight $(n=7,6.8 \%)$. There was no significant difference in average height, weight, or obesity of participants according to degree of sweetness preferences.

Mean age of the parents was $38.2 \pm 6.6$ years, with mothers of children being the dominant responders (87 mothers, $84.5 \%$ ). Education levels of parents were as follows: up to high school ( $n=37,36 \%)$, college or university $(n=64,62.1 \%)$, and graduate school ( $n=2,1.9 \%)$. Infant feeding practice for children included breast-feeding ( $n=34,33 \%)$, formula feeding ( $n=21,20.4 \%$ ), and combination feeding ( $n=48,46.6 \%$ ). There were no significant inter-cluster differences for sweetness preference amongst the participants.

Sweetness preference, sweets intake frequency, sweets restriction and nutrition quotient of children

Results comparing the sweetness preference, sweets intake frequency (times per week), sweets restriction and NQ of children in each cluster distinguished by different degrees of sweetness preference are presented in Table 2 . These variables showed significant differences between clusters. In terms of sweetness preference, preferences for higher concentration of sugar content was found to be concentrated in cluster $1(0.42$ M: $35 \%, 0.61 \mathrm{M}: 65 \%)$ whereas the sweetness preference for lower concentration of sugar content $(0.14 \mathrm{M}$ : $9.5 \%$; $0.20 \mathrm{M}$ : 9.5\%; $0.29 \mathrm{M}: 81 \%)$ was concentrated in cluster $2(P<0.001)$. Comparing the sweets intake frequency in each group, cluster 1 consumed sweets $8.2 \pm 14.0$ times per week while cluster 2 consumption was $2.8 \pm 4.9$ times per week $(P<0.01)$. Among the sweets items considered, sweet bread $(P<0.05)$ and ice cream $(P<0.05)$ exhibited significant differences in frequency of intake. Comparing the sweets restriction in each cluster, cluster 1 had lower restriction from parents (cluster 1: $3.2 \pm 0.7$, cluster 2: $2.9 \pm 0.6)(P<0.05)$.

The total score of NQ was $52.6 \pm 13.0$ for cluster 1 and 59.2 \pm 12.7 for cluster $2(P<0.01)$. NQ revealed significant inter-group differences in terms of its sub-variables of moderation (cluster 1: $60.2 \pm 12.0$, cluster $2: 66.0 \pm 11.2$ ) and practice (cluster 1: 51.7 \pm 15.9 , cluster $2: 63.5 \pm 20.0)(P<0.05$ and $P<0.01$, respectively). 
Table 1. General characteristics of subjects comparing clusters

\begin{tabular}{|c|c|c|c|c|c|}
\hline \multicolumn{2}{|c|}{ Variables } & Total & $\begin{array}{c}\text { Cluster } 1^{1)} \\
(\mathrm{n}=40)\end{array}$ & $\begin{array}{c}\text { Cluster } 2 \\
(n=63)\end{array}$ & $t / x^{2}$ \\
\hline \multicolumn{6}{|l|}{ Children } \\
\hline Age (yrs) & & $6.3 \pm 0.5^{2)}$ & $6.3 \pm 0.5$ & $6.4 \pm 0.5$ & 0.801 \\
\hline \multirow[t]{2}{*}{ Gender } & Boys & $51(49.5)^{3)}$ & $16(40.0)$ & 35 (55.6) & \multirow[t]{2}{*}{2.368} \\
\hline & Girls & $52(50.5)$ & $24(60.0)$ & $28(44.4)$ & \\
\hline Height (cm) & & $111.7 \pm 6.4$ & $111.7 \pm 6.4$ & $111.6 \pm 6.7$ & 0.062 \\
\hline Weight (kg) & & $20.1 \pm 3.2$ & $20.3 \pm 3.2$ & $19.9 \pm 3.1$ & 0.695 \\
\hline \multirow{3}{*}{$\begin{array}{l}\text { BMI percentile } \\
\quad(\text { Body mass index \%ile) }\end{array}$} & Under & $10(9.7)$ & $2(5.0)$ & $8(12.7)$ & \multirow[t]{3}{*}{3.271} \\
\hline & Normal & $86(83.5)$ & $35(87.5)$ & $51(81.0)$ & \\
\hline & Overweight & $7(6.8)$ & $3(7.5)$ & $4(6.3)$ & \\
\hline \multicolumn{6}{|l|}{ Guardians } \\
\hline Age (yrs) & & $38.2 \pm 6.6$ & $36.8 \pm 7.4$ & $39.1 \pm 5.9$ & 1.683 \\
\hline \multirow[t]{4}{*}{ Respondents } & Mother & $87(84.5)$ & $35(87.5)$ & $52(82.5)$ & \multirow[t]{4}{*}{1.599} \\
\hline & Father & $12(11.7)$ & $4(10.0)$ & $8(12.7)$ & \\
\hline & Grand parents & $2(1.9)$ & $1(2.5)$ & $1(1.6)$ & \\
\hline & Other & $2(1.9)$ & $0(0.0)$ & $2(3.2)$ & \\
\hline \multirow[t]{3}{*}{ Education levels } & $\leq$ High school & $37(36.0)$ & $17(42.5)$ & $20(31.7)$ & \multirow[t]{3}{*}{1.429} \\
\hline & College & $64(62.1)$ & $22(55.0)$ & $42(66.7)$ & \\
\hline & Graduate school & $2(1.9)$ & $1(2.5)$ & $1(1.6)$ & \\
\hline \multirow[t]{3}{*}{ Infant feeding practice } & Breast feeing & $34(33.0)$ & $14(35.0)$ & $20(31.8)$ & \multirow[t]{3}{*}{0.357} \\
\hline & Formula feeding & $21(20.4)$ & $7(17.5)$ & $14(22.2)$ & \\
\hline & Combination feeding & $48(46.6)$ & $19(47.5)$ & $29(46.0)$ & \\
\hline
\end{tabular}

${ }^{1)}$ Cluster 1: high preference for sweetness group, Cluster 2: low preference for sweetness group

2) Mean \pm SD

${ }^{3)} \mathrm{n}(\%)$

4) BMl percentile based on growth charts for Korean young children and adolescents (2007); Underweight: BMl percentile <5; Normal weight: $5 \leq$ BMl percentile < 85; Overweight: $85 \leq \mathrm{BMl}$ percentile.

Table 2. Comparison of sweetness preference, sweets intake frequency, sweets restriction and nutrition quotient of children

\begin{tabular}{|c|c|c|c|c|}
\hline & Variables & $\begin{array}{c}\text { Cluster } 1^{1)} \\
(\mathrm{n}=40)\end{array}$ & $\begin{array}{c}\text { Cluster } 2 \\
(n=63)\end{array}$ & $\mathrm{t}$ \\
\hline \multirow[t]{5}{*}{ Sweetness preference ${ }^{2)}$} & 1 & $0(0)^{3)}$ & $6(9.5)$ & \multirow{5}{*}{$103.000^{* * *}$} \\
\hline & 2 & $0(0)$ & $6(9.5)$ & \\
\hline & 3 & $0(0)$ & $51(81.0)$ & \\
\hline & 4 & $14(35.0)$ & $0(0)$ & \\
\hline & 5 & $26(65.0)$ & $0(0)$ & \\
\hline \multirow{9}{*}{$\begin{array}{l}\text { Sweets intake frequency } \\
\text { (times per week) }\end{array}$} & Total & $8.2 \pm 14.0^{4)}$ & $2.8 \pm 4.9$ & $2.835^{* *}$ \\
\hline & Sweet cookies & $1.8 \pm 4.5$ & $0.7 \pm 2.2$ & 1.688 \\
\hline & Candy & $1.7 \pm 4.6$ & $0.5 \pm 2.2$ & 1.729 \\
\hline & Sweet bread & $0.4 \pm 0.3$ & $0.2 \pm 0.3$ & $2.416^{*}$ \\
\hline & Chocolate & $0.3 \pm 0.3$ & $0.3 \pm 0.3$ & 0.415 \\
\hline & Sweet dairy drinks & $0.8 \pm 2.2$ & $0.4 \pm 1.5$ & 1.001 \\
\hline & Ice cream & $1.7 \pm 4.5$ & $0.3 \pm 0.3$ & $2.370^{*}$ \\
\hline & Sweet drinks & $0.9 \pm 3.2$ & $0.2 \pm 0.2$ & 1.802 \\
\hline & Carbonated drinks & $0.7 \pm 3.3$ & $0.1 \pm 0.2$ & 1.337 \\
\hline \multirow[t]{9}{*}{ Sweets restriction ${ }^{5)}$} & Total & $3.2 \pm 0.7$ & $2.9 \pm 0.6$ & $1.992^{*}$ \\
\hline & Sweet cookies & $3.3 \pm 0.8$ & $3.0 \pm 0.7$ & 1.571 \\
\hline & Candy & $3.2 \pm 0.9$ & $2.9 \pm 0.9$ & 1.543 \\
\hline & Sweet bread & $3.5 \pm 0.8$ & $2.9 \pm 0.9$ & $3.504^{* *}$ \\
\hline & Chocolate & $3.3 \pm 0.9$ & $2.9 \pm 0.9$ & $2.101^{*}$ \\
\hline & Sweet dairy drinks & $3.1 \pm 0.8$ & $3.0 \pm 0.8$ & 0.843 \\
\hline & Ice cream & $3.2 \pm 1.2$ & $3.1 \pm 0.8$ & 0.617 \\
\hline & Sweet drinks & $3.1 \pm 1.0$ & $3.0 \pm 0.8$ & 0.739 \\
\hline & Carbonated drinks & $2.5 \pm 1.2$ & $2.3 \pm 1.0$ & 0.778 \\
\hline
\end{tabular}


Table 2. continued

\begin{tabular}{|c|c|c|c|c|}
\hline & Variables & $\begin{array}{c}\text { Cluster } 1^{1)} \\
(\mathrm{n}=40)\end{array}$ & $\begin{array}{c}\text { Cluster } 2 \\
(n=63)\end{array}$ & $\mathrm{t}$ \\
\hline \multirow[t]{6}{*}{ Nutrition quotient ${ }^{6)}$} & Total & $52.6 \pm 13.0$ & $59.2 \pm 12.7$ & $2.578^{*}$ \\
\hline & Balance & $47.7 \pm 15.4$ & $50.1 \pm 16.6$ & 0.725 \\
\hline & Diversity & $48.6 \pm 25.6$ & $56.7 \pm 23.5$ & 1.651 \\
\hline & Moderation & $60.2 \pm 12.0$ & $66.0 \pm 11.2$ & $2.477^{*}$ \\
\hline & Regularity & $59.8 \pm 21.6$ & $64.3 \pm 16.5$ & 1.173 \\
\hline & Practice & $51.7 \pm 15.9$ & $63.5 \pm 20.0$ & $3.172^{* *}$ \\
\hline
\end{tabular}

1) Cluster 1: high preference for sweetness, Cluster 2: low preference for sweetness

2) ' 1 ' means the lowest sweetness among samples, ' 5 ' means the highest sweetness among samples (sugar concentration: $0.14 \mathrm{M}, 0.20 \mathrm{M}, 0.29 \mathrm{M}, 0.42 \mathrm{M}, 0.61 \mathrm{M}$ ) ${ }^{3)} \mathrm{n}(\%)$

4) Mean $\pm \mathrm{SD}$

5) Parents answered whether their children freely choose specified sweet items. 5 -point Likert scale (' 1 ' never free to choose, ' 5 ' always free to choose)

6) Nutrition quotient score range: 0-100 ('<10' lowest, '10-24' low, '25-74' moderate, '75-89' high, ' $\geq 90$ ' highest)

${ }^{\star} P<0.05,{ }^{* \star} P<0.01,{ }^{* \star *} P<0.001$

Table 3. Comparison of parent's variables based on the theory of planned behavior

\begin{tabular}{|c|c|c|c|}
\hline Variables & $\begin{array}{c}\text { Cluster } 1^{1)} \\
(\mathrm{n}=40)\end{array}$ & $\begin{array}{c}\text { Cluster } 2 \\
(n=63)\end{array}$ & t-value \\
\hline \multicolumn{4}{|l|}{ Behavioral intention } \\
\hline I always try to give fewer sweets to child & $3.4 \pm 0.8^{2)}$ & $3.8 \pm 0.7$ & $2.528^{*}$ \\
\hline Affective attitude & $3.7 \pm 0.5$ & $3.3 \pm 0.6$ & $3.748^{* * *}$ \\
\hline Eating sweet is one of the child's favorite things & $3.8 \pm 0.6$ & $3.5 \pm 0.6$ & $2.299^{*}$ \\
\hline Sweet makes child happy & $3.7 \pm 0.6$ & $3.1 \pm 0.8$ & $3.780^{* * *}$ \\
\hline Cognitive attitude & $3.3 \pm 0.7$ & $3.3 \pm 0.8$ & 0.316 \\
\hline Child will grow fat after eating too many sweets & $3.5 \pm 1.0$ & $3.5 \pm 1.0$ & 0.144 \\
\hline Child will eat less healthy food, when he/she has too many sweets & $3.4 \pm 0.9$ & $3.6 \pm 0.9$ & 0.846 \\
\hline Child will become hyperactive from eating too many sweets & $2.9 \pm 1.0$ & $2.9 \pm 1.5$ & 0.174 \\
\hline Subjective norm & $2.8 \pm 0.9$ & $2.7 \pm 0.9$ & 0.799 \\
\hline Child does not like sweet unless teacher gives child sweet & $2.7 \pm 0.9$ & $2.6 \pm 0.9$ & 0.476 \\
\hline Child does not like sweet unless child's peer eats sweet & $2.9 \pm 1.0$ & $2.7 \pm 0.9$ & 1.040 \\
\hline \multicolumn{4}{|l|}{ Perceived behavioral control } \\
\hline I can control eating of sweets & $3.8 \pm 0.7$ & $3.9 \pm 0.7$ & 0.909 \\
\hline
\end{tabular}

1) Cluster 1: high preference for sweetness group, Cluster 2: low preference for sweetness group

${ }^{2)}$ Mean \pm SD, 5-point Likert scale (' 1 ' strongly disagree, ' 5 ' strongly agree, affective attitude as positive feeling, cognitive attitude as negative outcome expectation, subjective norm as parent's beliefs that other people's effect in eating sweets.)

${ }^{\star} P<0.05,{ }^{\star \star \star} P<0.001$.

Table 4. Comparison of parenting practice with children's sweetness preference

\begin{tabular}{|c|c|c|c|}
\hline Variables & $\begin{array}{c}\text { Cluster } 1^{1)} \\
(\mathrm{n}=40)\end{array}$ & $\begin{array}{c}\text { Cluster } 2 \\
(n=63)\end{array}$ & t-value \\
\hline Feeding practice & $2.6 \pm 0.6^{2)}$ & $2.3 \pm 0.4$ & $2.710^{*}$ \\
\hline I allow my child to freely choose sweets whenever he/she wants & $3.1 \pm 0.7$ & $2.9 \pm 0.6$ & $1.992^{*}$ \\
\hline I feed child sweets because child likes sweets & $2.5 \pm 0.8$ & $2.1 \pm 0.6$ & $2.735^{* *}$ \\
\hline I give sweets to child when he/ she does not like the food I serve & $2.1 \pm 0.8$ & $2.0 \pm 0.5$ & 0.879 \\
\hline Parenting attitude & $3.8 \pm 0.5$ & $3.9 \pm 0.4$ & 1.199 \\
\hline I can teach child to eat less sweets & $3.6 \pm 0.6$ & $3.9 \pm 0.5$ & $2.177^{*}$ \\
\hline Nothing I can do about child just like sweets ${ }^{3)}$ & $3.9 \pm 0.6$ & $4.1 \pm 0.5$ & 1.036 \\
\hline As long as my child brushes his/her teeth, I do not have to limit his/her sweets consumption & $3.9 \pm 0.8$ & $3.9 \pm 0.7$ & 0.134 \\
\hline \multicolumn{4}{|l|}{ Reward } \\
\hline I use sweets as a reward & $2.7 \pm 0.9$ & $2.1 \pm 0.6$ & $3.502^{* *}$ \\
\hline
\end{tabular}

\footnotetext{
1) Cluster 1: high preference for sweetness, Cluster 2: low preference for sweetness

${ }^{2)}$ Mean \pm SD, 5-point Likert scale (' 1 ' strongly disagree, ' 5 ' strongly agree; feeding practice as restriction in sweets, parenting attitude as parent's judgement for positive parent-child interaction, reward as using as a reward)

3) This item coded reversely

* $P<0.05$, ${ }^{* \star} P<0.01$.
} 
Table 5. Comparison of sweetness preference, sweets intake frequency and nutrition quotient of children, with respect to sweets restriction imposed by parents

\begin{tabular}{lccc}
\hline \multicolumn{1}{c}{ Variables } & $\begin{array}{c}\text { Low restriction } \\
(\mathrm{n}=79)\end{array}$ & $\begin{array}{c}\text { High restriction } \\
(\mathrm{n}=24)\end{array}$ & t-value \\
\hline Sweetness preference & $15.2 \pm 4.9^{2)}$ & $12.1 \pm 5.1$ & $2.579^{*}$ \\
Sweets intake frequency & $11.1 \pm 16.5^{3)}$ & $3.0 \pm 5.4$ & $2.373^{*}$ \\
Nutrition quotient & $50.7 \pm 12.8^{4)}$ & $58.4 \pm 12.8$ & $2.565^{*}$ \\
\hline
\end{tabular}

1) Low restriction (mean-3.14), high restriction (mean-2.24): 5-point Likert scale

(' 1 ' always restrict, ' 5 ' never restrict)

2) Sugar content $(\mathrm{g} / 100 \mathrm{~mL})$, mean $\pm \mathrm{SD}$.

${ }^{3}$ Sweets intake frequency: times per week

4) Nutrition quotient score range: 0-100 ('<10' lowest, '10-24' low, '25-74'

moderate, '75-89' high, ' $\geq 90$ ' highest)

* $P<0.05$

Comparison of sweetness preferences of children and parent variables

Effects of parenting variables based on the theory of planned behavior for each cluster are presented in Table 3. BI (I always try to give less sweets to the child) of parents in cluster 2 appeared higher than that of cluster $1(P<0.05)$. Parents in cluster 1 had higher scores than parents in cluster 2 when considering affective attitude toward sweets $(P<0.001)$, including all sub-variables commonly exhibiting significant inter-group differences such as 'eating sweets is one of my child's favorite things' $(P<0.05)$ and 'sweets make the child happy' $(P<0.001)$. Cognitive attitude, subjective norm, and perceived behavior control rendered no significant inter-group differences between the clusters.

Comparison of sweetness preferences of children and parenting practice

Results of parenting practices in cluster 1 and cluster 2 are presented in Table 4. Parents in cluster 1 exhibited rather permissive feeding practices of providing sweets $(P<0.05)$ with the degree of reward dominated by sweets $(P<0.01)$. Parents in cluster 1 also exhibited more positive replies to the following questions belonging to feeding practices: 'I allow my child to freely choose sweets whenever he/she wants.' $(P<0.05)$ and 'I feed child sweets because child likes sweets' $(P<0.01)$. In the sub-category of parenting attitude, significant intergroup difference $(P<0.05)$ was found for the following question: 'I can teach child to eat sweets less'. Parents of children preferring lower concentrations of sugar content showed more efforts to educate their children to control intake of sweets.

The sweetness preference, sweets intake frequency, and NQ of children were compared with sweets restrictions imposed by parents. Results of the comparison are presented in Table 5. Children of parents with lower restriction for sweets intake exhibited higher frequency of consumption $(P<0.05)$, higher sweetness preference $(P<0.05)$, and lower NQ $(P<0.05)$, compared to children of parents with higher degrees of sweets restriction.

Correlation between sweetness preference, sweets intake frequency and nutrition quotient of children

Results analyzed for correlating sweetness preferences, sweets intake frequency and NQ of children are summarized in Table 6 . The sweetness preference of children showed a positive correlation with frequency of sweets intake $(r=0.221, P<0.05)$, but is negatively correlated with NQ $(r=-0.265, P<0.01)$. In the sub-categories of NQ, significant correlations were found for diversity $(r=-0.210, P<0.05)$, moderation $(r=-0.259, P<0.01)$ and practice $(r=-0.278, P<0.01)$. Total scores of NQ $(r=-0.204$ $P<0.05)$, moderation $(r=-0.409, P<0.01)$, and regularity $(r=$ -0.225, $P<0.05$ ) exhibited significant correlation with sweets intake frequency of children.

Table 6. Pearson correlation coefficient for sweetness preference, sweets intake frequency and nutrition quotient of children

\begin{tabular}{lcccccc}
\hline \multicolumn{1}{c}{ Variables } & $\begin{array}{c}\text { Sweets intake } \\
\text { frequency }\end{array}$ & Nutrition quotient & Balance & Diversity & Moderation \\
\hline Sweetness preference & $0.221^{*}$ & $-0.265^{* *}$ & -0.155 & $-0.210^{*}$ & $-0.259^{* *}$ \\
Sweets intake frequency & & $-0.204^{*}$ & -0.030 & -0.074 & -0.081 & $-0.409^{* *}$ \\
\hline
\end{tabular}

* $P<0.05,{ }^{*} P<0.01$

Table 7. Pearson correlation coefficient for sweetness preference and sweets intake frequency of children and parenting variables

\begin{tabular}{|c|c|c|c|c|c|c|c|c|}
\hline Variables & $\begin{array}{c}\text { Behavioral } \\
\text { intention }\end{array}$ & $\begin{array}{l}\text { Affective } \\
\text { attitude }\end{array}$ & $\begin{array}{l}\text { Cognitive } \\
\text { attitude }\end{array}$ & Subjective norm & $\begin{array}{c}\text { Perceived } \\
\text { behavioral } \\
\text { control }\end{array}$ & $\begin{array}{l}\text { Feeding } \\
\text { practice }\end{array}$ & $\begin{array}{l}\text { Parenting } \\
\text { attitude }\end{array}$ & Reward \\
\hline \multicolumn{9}{|l|}{ Children } \\
\hline Sweetness preference & $-0.209 *$ & $0.302^{* *}$ & -0.020 & -0.017 & -0.033 & $0.232^{*}$ & -0.048 & $0.265^{* *}$ \\
\hline Sweets intake frequency & -0.027 & 0.173 & -0.030 & -0.091 & 0.057 & $0.390^{* *}$ & -0.141 & $0.267^{* *}$ \\
\hline \multicolumn{9}{|l|}{ Guardians } \\
\hline Behavioral intention & & $-0.282^{* *}$ & 0.187 & $0.203^{*}$ & 0.134 & $-0.380^{* *}$ & $0.433^{* *}$ & -0.155 \\
\hline Affective attitude & & & 0.115 & -0.112 & 0.065 & $0.394^{* *}$ & $-0.202^{*}$ & $0.437^{* *}$ \\
\hline Cognitive attitude & & & & $0.195^{*}$ & -0.170 & -0.007 & 0.123 & 0.023 \\
\hline Subjective norm & & & & & 0.090 & $-0.220^{*}$ & 0.121 & 0.033 \\
\hline $\begin{array}{l}\text { Perceived behavioral } \\
\text { control }\end{array}$ & & & & & & -0.047 & 0.151 & 0.017 \\
\hline Feeding practice & & & & & & & $-0.516^{* *}$ & $0.508^{* *}$ \\
\hline Parenting attitude & & & & & & & & $-0.407^{* *}$ \\
\hline
\end{tabular}

* $P<0.05,{ }^{* *} P<0.01$ 
Correlation between sweetness preference and sweets intake frequency of children and parenting variables

Correlations between sweetness preference, sweets intake frequency, and parenting variables in each group are presented in Table 7. Sweetness preference of children was negatively correlation with $\mathrm{Bl}$ of parents $(r=-0.209, P<0.05)$, but positively correlated with affective attitude $(r=0.302, P<0.01)$, feeding practice $(r=0.232, P<0.05)$, and reward $(r=0.265, P<0.01)$ of parents. Frequency of sweets intake in children showed no significant correlation with $\mathrm{Bl}$ of parents. However, it showed positive correlations with feeding practice $(r=0.390, P<0.01)$ and reward $(r=0.267, P<0.01)$. The $\mathrm{BI}$ of parents manifested significant correlations with affective attitude $(r=-0.282, P<$ $0.01)$, subjective norm $(r=0.203, P<0.05)$, feeding practice $(r$ $=-0.380, P<0.01)$, and parenting attitudes $(r=0.433, P<0.01)$.

\section{DISCUSSION}

The present study explores the interaction between parenting and sweets preferences of children. Furthermore, we suggest strategies to help construct a desirable dietary environment for children, and effective educational strategies for parents to reduce sugar intake by exploring parenting factors. Accessibility and availability of foods for young children depends greatly on their parents [6]. Thus, diverse approaches for developing effective educational strategies for parents are required in the contemporary dietary environment inundated with cheap and palatable foods having high energy density.

In the present study, no significant difference was observed for sweetness preferences of children in terms of varied infant feeding practice, such as breast-feeding, formula feeding, or combination feeding. It has previously been reported that preference for salty or bitter taste depends on the frequency of exposure to flavors in the amniotic fluid during the fetal period, or in breast milk $[2,10]$. However, there is no clarification on the dependency of sweetness preferences of infants or young children. In the current study, varied infant feeding practices rendered no significant differences for sweetness preferences of children. Subsequent studies focusing on dietary patterns or food preference of mothers are needed to obtain the necessary information to clarify the relationship with sweetness preferences of children.

Scores of NQ and sweets intake frequency of children were also compared. NQ for children is a tool designed to appraise dietary lives and nutritional state of children through answers to simple questions $[16,17]$. Preference for sweet taste with higher concentrations of sugar, as well as sweets intake frequency of children who preferred sweet taste with higher concentration of sugar content, appeared to be higher in children with lower NQ scores. In the correlation analysis, sweetness preference of children exhibited negative correlations with scores of NQ. The sweets intake frequency also showed a negative correlation with NQ score. Our study indicates that the frequency of sweets intake might be associated with elevated levels of sweetness preference in children. This would promote nutritional imbalance and decrease practices of healthy dietary life, resulting in negative effects on desirable growth and development of children. Frary et al. [21] reported that excessive intake of drinks containing sugar content (except for processed milk drinks), sweet breads, or cookies negatively affect the intake of minerals such as calcium, folic acid, and iron. In the contemporary obesogenic environment, people are able to easily select foods with high energy-density. People who prefer sweet taste are thereby risking incident health problems owing to excessive accumulation of sugar content from frequent intake of sweet foods. Thus, frequent provision of sweets as a light meal or a snack for children needs to be reconsidered, since these sweets are associated with the sweetness preference and dietary quality in children, as presented in the current study.

Accessibility and availability of foods for children are usually determined by parents. Thus, examining the behavioral motivation of parents associated with the selection of sweet foods, snacks, or light meals could help in developing educational strategies to establish desirable practices in parents. The theory of planned behavior can help nutritional educators develop useful strategies capable of promoting changes in the behavioral motivation of individuals by understanding their $\mathrm{Bl}$, belief, and attitude. BI has a significant relationship with the possibility of behavioral implementation [2]. Considering the $\mathrm{Bl}$ of parents who give lesser sweets to their children, the cluster of children with higher sweetness preference exhibited lower levels of parental Bl for restraining sweet snacks for their children. The cluster of children with higher sweetness preferences also manifested higher level of intake frequency of sweet foods under normal conditions. These results indicate an association between the $\mathrm{Bl}$ of parents and sweetness preferences and frequency of sweets intake in children. The $\mathrm{BI}$ of parents reveal a negative correlation with the affective attitude for sweets, and a positive correlation with subjective norm. Affective attitude refers to emotional reaction and sense of expectation of sweet snacks, whereas subjective norm is regarded as a belief on thought and behavior relevant to sweet snacks of importance [2]. Furthermore, we observed that attitude and belief of parents are also relevant to those of children, and affect the accessibility and availability of foods [22]. In particular, the emotional attitude of parents was found to be significantly associated with the sweetness preference in children [20]. Sugar intake is known to have positive effects on the psychological state of most people [23]. Hence, the sweetness preference of people can be regarded as a biological disposition resulting from adaptation to the environment. A negative recognition of emotional attitude preferring sweet taste is comparably difficult. Therefore, diverse approaches combined with reasonable amount of natural foods free from added sugar content need to be repeatedly presented to preschool and kindergarten children, to facilitate replacing the current sweet snacks provided to them. Besides, the level of recognition for "excessive intake of sugar content" of parents also needs to be elevated, along with parental education on how to restrain intake of undesirable foods appropriate for the contemporary obesogenic environment. In addition, policies that support the expansion for quality certification of favorite foods for children need to be selected by parents, developed, and implemented.

Results obtained from the current study revealed significant effects of feeding practice and reward of parents on the sweetness preferences amongst children. Parents of children with 
higher sweetness preference appeared to be more permissive in providing their children with sweet snacks, together with more instances of reward exploiting sweet snacks. These results suggest that feeding practice, which has been emphasized by several studies $[7,10]$, could be a determinant constituting preference for foods of children. The "feeding practice" of parents signifies a concrete control strategy employed by parents, relevant to formation of dietary lives of their children, such as restriction on access to sweets, emphasizing intake of healthy foods, and set up of environment promoting intake of vegetables and fruits [7]. In the present study, children of parents showing higher degree of control over intake of sweet snacks appeared to have lower levels of sweets intake frequency and preference for sweets, concomitant with higher level of nutrition quotient. Proper restriction on the intake of sweets for children thus seems to be effective in decreasing the level of preference for sweets. However, excessive control over intake of sweet foods by parents may contrarily trigger a preference for foods with higher concentration of sugar content [24]. It may also cause overeating or less self-control over dietary behaviors in preschoolers [25]. In the meantime, there is a report on the daily intake of sugar content, indifferent to the level of control over intake of sweets [1]. This might be attributable to different patterns of food intake in children from different nurturing environments such as daycare centers and kindergartens, other than the rearing environment directly controlled by parents. However, it is confirmed that preference for foods in children varies depending on different parenting practice.

Parenting styles are distinguished into four types, depending on the control over their children and corresponding responses: authoritarian, authoritative, permissive, and neglectful. Most parents have features of mixed parenting styles. The authoritative style exhibits reactions and affection pertinent to dietary behaviors of their children, together with presentation of definite guidelines and permissible limit for dietary lives of their children. It encourages desirable practices for food preferences and dietary behaviors [1,24].

The "reward" given by parents is frequently employed for instrumental feeding ("If you eat A, you can have B"). It is then divided into tangible reward (using stickers or foods, etc.) and intangible reward (of praise or admiration of peer group, etc.). Positive and negative consequences resulting from rewards contradict each other on the motivation of expected behaviors. In particular, it is reported that sweet foods employed for rewards result in increased preference for sweet foods, since their application as a reward creates positive emotions [26]. By nature, most humans are disposed towards sweetness preference, especially children, who prefer sweet foods containing a higher density of energy [26]. In the changing dietary environment, where excessive intake of saccharide is more probable due to convenient accessibility to beverages, cookies, and breads, presenting sweet snacks as a reward needs to be avoided to help facilitate desirable growth and development of children.

Significant differences in preference for sweets and frequency of sweets intake of children depending on $\mathrm{Bl}$ of parents, were identified in the present study. Thus, educational strategies pertinent to components exhibiting correlations with significant consequences need to be developed to create positive effects on the $\mathrm{Bl}$ of parents. Positive emotional attitudes of parents toward sweet snacks might be associated with permissive feeding practice, even if the permissive attitude of parents employed sweets as a means of reward. The permissive feeding practice of parents is implicated in increasing intake of sweet drinks and frequency of sweets in children, whereas the authoritative parenting style of parents has a positive effect on intake of dairy products [24]. To reduce the intake of sweets in children, there is a need to furnish access guidelines of sweets for children and pertinent parenting practices to control accessibility of sweets. BI of parents oriented to replace sweets with other healthy snacks also needs to be encouraged. Further studies are required to present educational strategies to parents, based on social support.

This study has some limitations. First, in the current environment wherein daycare centers and kindergartens are spread widely, foods for children prepared therein may significantly affect children. However, the effect of sweet snacks or light meals provided for children in daycare and kindergarten on the development of sweetness preference of children was not analyzed. Therefore, sources of effect that can result in the formation of current preferences to sweet taste in children identified in the present study need to be further clarified, including those of different parenting variables, through further studies. Second, the survey that employed self-administered questionnaire to investigate the frequency of provision of sweet snacks for children lacked concrete amount of daily intake of saccharide for children. Therefore, comparison with recommended amount of daily intake of saccharide according to various levels of sweetness preferences was not performed. The actual level of daily intake of saccharide through sweet snacks corresponding to different levels of preference for sweets and frequency of intake of sweet foods in the subjects group of children needs to be clarified through further studies to present more persuasive information to decrease the intake of saccharide in children.

\section{ACKNOWLEDGEMENTS}

We sincerely thank Ms. Yeonjeong Seo, leader of Center for Changwon Children's Foodservice Management, for contributing to this survey.

\section{CONFLICT OF INTEREST}

The authors have no potential conflicts of interests to disclose, relevant to this study.

\section{ORCID}

Taejung Woo: https://orcid.org/0000-0002-4883-2047

Kyung-Hea Lee: https://orcid.org/0000-0003-0444-4824

\section{REFERENCES}

1. Liem DG, Mars $M$, De Graaf $C$. Sweet preferences and sugar consumption of 4- and 5-year-old children: role of parents. Appetite 2004;43:235-45 
2. Contento IR. Nutrition Education: Linking Research, Theory, and Practice. 3rd ed. Burlington (MA): Jones \& Bartlett Learning; 2016. p.31-37, 75, 108, 111.

3. Ministry of Health and Welfare of Korea, Korea Centers for Disease Control and Prevention. Korea Health Statistics 2016: Korea National Health and Nutrition Examination Survey (KNHANES VII-1). Cheongju: Korea Centers for Disease Control and Prevention; 2017.

4. Te Morenga LA, Howatson AJ, Jones RM, Mann J. Dietary sugars and cardiometabolic risk: systematic review and meta-analyses of randomized controlled trials of the effects on blood pressure and lipids. Am J Clin Nutr 2014;100:65-79.

5. Ministry of Health and Welfare of Korea; The Korean Nutrition Society. Dietary References Intakes for Korean 2015. Seoul: The Korean Nutrition Society; 2015.

6. Battram DS, Piché L, Beynon C, Kurtz J, He M. Sugar-sweetened beverages children's perceptions, factors of influence, and suggestions for reducing intake. J Nutr Educ Behav 2016;48:27-34.e1.

7. Scaglioni S, Arrizza C, Vecchi F, Tedeschi S. Determinants of children's eating behavior. Am J Clin Nutr 2011;94:2006S-2011S.

8. Park MY, Park PS. Factors related to eating habits and nutrition status of mother affecting on body mass index of children aged 15 years: data from the fifth Korea National Health and Nutrition Examination Survey, 20102011. Korean J Community Nutr 2016;21: 102-11.

9. Dennis E, Kang M, Han SN. Relation between beverage consumption pattern and metabolic syndrome among healthy Korean adults. Korean J Community Nutr 2017;22:441-55.

10. De Cosmi V, Scaglioni S, Agostoni C. Early taste experiences and later food choices. Nutrients 2017;9:1-9.

11. Reed DR, McDaniel AH. The human sweet tooth. BMC Oral Health 2006;6 Suppl 1:S17.

12. Zoellner J, Estabrooks PA, Davy BM, Chen YC, You W. Exploring the theory of planned behavior to explain sugar-sweetened beverage consumption. J Nutr Educ Behav 2012;44:172-7.

13. Bazillier $C$, Verlhiac JF, Mallet $P$, Rouëssé J. Predictors of intentions to eat healthily in 8-9-year-old children. J Cancer Educ 2011;26: 572-6.

14. Musher-Eizenman D, Holub S. Comprehensive feeding practices questionnaire: validation of a new measure of parental feeding practices. J Pediatr Psychol 2007;32:960-72.

15. Ministry of Food and Drug Safety. Public announcement No. 200925 [Internet]. Cheongju: Ministry of Food and Drug Safety; 2009 [cited 2016 January 10]. Available from: http://www.mfds.go.kr/brd/.

16. Kang MH, Lee JS, Kim HY, Kwon S, Choi YS, Chung HR, Kwak TK, Cho $\mathrm{YH}$. Selecting items of a food behavior checklist for the development of Nutrition Quotient (NQ) for children. Korean J Nutr 2012;45:372-89.

17. Kim HY, Kwon S, Lee JS, Choi YS, Chung HR, Kwak TK, Park J, Kang $\mathrm{MH}$. Development of a nutrition quotient equation modeling for children and the evaluation of its construct validity. Korean $\mathrm{J}$ Nutr 2012;45:390-9.

18. Bae JM, Kang MH. Age difference in association between obesity and Nutrition Quotient scores of preschoolers and school children. J Nutr Health 2016;49:447-58.

19. Kim JH, Jung YH. Evaluation of food behavior and nutritional status of preschool children in Nowon-gu of Seoul by using Nutrition Quotient (NQ). Korean J Community Nutr 2014;19:1-11.

20. Takemi Y, Woo T. Comparison of sweetness preference and motivational factors between Korean and Japanese children. J Nutr Health 2017;50:53-63.

21. Frary $C D$, Johnson RK, Wang MQ. Children and adolescents' choices of foods and beverages high in added sugars are associated with intakes of key nutrients and food groups. J Adolesc Health 2004;34:56-63.

22. Patrick $\mathrm{H}$, Nicklas TA. A review of family and social determinants of children's eating patterns and diet quality. J Am Coll Nutr 2005;24:83-92.

23. Pilska M, Nesterowicz J. Emotional determinants of sweets consumption. J Nutr Health Sci 2016;3:405.

24. Vollmer RL, Mobley AR. Parenting styles, feeding styles, and their influence on child obesogenic behaviors and body weight. A review. Appetite 2013;71:232-41.

25. Savage JS, Fisher JO, Birch LL. Parental influence on eating behavior: conception to adolescence. J Law Med Ethics 2007;35:22-34.

26. Cooke $\sqcup$, Chambers LC, Añez EV, Wardle J. Facilitating or undermining? The effect of reward on food acceptance. A narrative review. Appetite 2011;57:493-7. 